\title{
ПРИМЕНЕНИЕ АКТИВИРОВАННОГО УГЛЯ ДЛЯ ГРУППОВОГО КОНЦЕНТРИРОВАНИЯ МИКРОЭЛЕМЕНТОВ ПРИ ХИМИКО-СПЕКТРАЛЬНОМ АНАЛИЗЕ ПОДЗЕМНЫХ ВОД
}

В практике гидрохимического анализа нередко возникает необходимость в определении большой группы микроэлементов. Для этой цели наиболее пригодны методы химико-спектрального анализа, заключающиеся в предварительном концентрировании микроэлементов из большого объема воды с последующим спектральным анализом концентрата. Однако два обстоятельства затрудняют успешное применение этих методов: 1) неконтролируемое изменение микро- и макросостава проб воды во время доставки их в лабораторию и хранения до выполнения анализа; 2) присутствие в воде растворимых органических веществ, в частности гумусовых кислот (Кузнецов и др., 1974), препятствующих количественному концентрированию микроэлементов из воды. Первое затруднение устраняется проведением концентрирования микроэлементов непосредственно на месте отбора пробы, а второе требует применения трудоемких способов для разложения органических веществ в лабораторных условиях. К сожалению, большинство надежных методов являются лабораторными.

Из методов группового концентрирования микроэлементов наиболее широкое распространение получили следующие: 1) выпаривание воды до сухого остатка (Гусяцкая, Логинова, 1956); 2) соосаждение микроэлементов с сульфидом кадмия (Миллер, Степанов, 1959) ; 3) экстрагирование диэтилдитиокарбаминатов и оксихинолятов металлов хлороформом (Еременко, 1969).

Общей чертой этих методов является проведение спектрального анализа концентрата путем сжигания его в кратере угольного электрода. Отсюда возникают многие трудности, так как интенсивность фракционированного испарения элементов из кратера и тем самым интенсивность спектральных линий в большой степени зависят от микро- и макросостава концентрата (Еременко, 1969).

В ряде других работ (Кибисов и др., 1970; Кубасова и др., 1970) показано, что для уменьшения фракционированного испарения элементов и подавления влияния произвольного состава проб на результаты анализа необходимо: 1) тонкое измельчение пробы (до нескольких мкм); 2) непрерывное введение порошка пробы в дугу путем вдувания; 3) примененне спектроскопического буфера (хлористого натрия) для стабилизации 
температуры дуги. Однако эти способы были применены не к анализу концентратов микроэлементов природных вод.

В настоящей работе ставилась задача разработки нового варианта химико-спектрального анализа подземных вод с уделением особого внимания изучению возможностей концентрирования микроэлементов на месте отбора пробы, упрощению предварительной подготовки концентрата к спектральному анализу и проведению его методом просыпки концентрата в дугу с соблюдением вышеперечисленных условий.

В качестве коллектора для концентрирования микроэлементов выбран активированный уголь из следующих соображений: 1) этот адсорбент является надежной спектроскопической основой для микроэлементов и не требует для сжигания в дуге сложной подготовки; 2) при необходимости можно угольный концентрат озолять и тем самым существенно повышать чувствительность анализа; 3) при его применении отпадает необходимость в разложении органических веществ воды, так как он адсорбирует природные и синтетические органические соединения (Лурье, Рыбникова, 1974; Когановский, Клименко, 1974), в составе которых нередко могут находиться и микроэлементы (Кузнецов и др., 1974); 4) активированный уголь в сочетании с органическими реактивами уже применялся для концентрирования микроэлементов из разных материалов (Андреев, Чумаченко, 1961; Цгэн Сянь-Фу и др., 1963; Тарковская и др., 1965; Jackwerth и др., 1974).

В перечисленных работах исследуемые растворы пропускались или через колонки, наполненные большим количеством крупнозернистого активированного угля, или через фильтры с углем. Микроэлементы вымывались из угля раствором кислоты. Однако непосредственное применение такого способа концентрирования не дает удовлетворительных результатов при решении поставленной задачи.

Нами разработана новая схема химико-спектрального ан ализа подземных вод. Концентрирование микроэлементов из $1 \Omega$ воды проводится на активированном угле марки ОУ в присутствии трех реактивов - 8-оксихинолина, таннина и тионалида (Митчел, 1961).

В отличие от вышеназванных методов концентрирования в данной схеме анализа применяется активированный уголь в виде очень тонкого порошка, который образует в воде весьма стойкую взвесь и обеспечивает равномерное распределение частиц угля по всему объему воды на длительное время. Общая поверхность такого пылевидного угольного порошка настолько больше поверхности стенок посуды, что адсорбцией разных форм микроэлементов на них можно пренебречь.

Второе отличие. Уголь не обрабатывается реактивами. Последние в виде ацетоновых растворов смешиваются с водой до прибавления угля. Такой прием обеспечивает адсорбцию микроэлементов и их соединений независимо от того, имеют ли эти соединения природное происхождение или образуются от взаимодействия с добавленными реактивами. Опыты с пробами вод, содержащих гумусовые кислоты, показали, что в угольный концентрат переходит около $60-80 \%$ от общего количества микроэлементов пробы и без введения реактивов, т. е. при данном способе концентрирования природные органические соединения не только не мешают, но и способствуют концентрированию микроэлементов. Активированный уголь без реактивов и природных органических веществ извлекает из воды при данных условиях анализа не более $20-30 \%$ от общего количества микроэлементов пробы.

Серией опытов установлено, что угольный концентрат можно оставлять в воде на $3-4$ суток, не опасаясь потерь микроэлементов. Это дает возможность прибавлять реактивы и уголь к пробе воды на месте ее 
отбора, а отделение концентрата проводить уже в лаборатории или на базе экспедиции. Для облегчения измерения объемов реактивов в полевых условиях применяются дозаторы.

Третье отличие. Тонкодисперсная взвесь угольного концентрата фильтруется с трудом, причем не исключено прохождение некоторой части взвеси через фильтр. Для получения быстрооседаемого и легкофильтруемого осадка с полным захватом в концентрат всех дисперсных частиц к взвеси угольного концентрата прибавляется флокулянт полиакриламид. Последний зарекомендовал себя эффективным средством не только для флокуляции угольных дисперсных систем (Благов и др., 1960): недавно были опубликованы данные о совместной флокуляции неактивного графитового порошка и коллоидов соединений микроэлементов с органическими реактивами (Каплан и др., 1974).

Совместное применение в настоящей схеме анализа трех групповых реагентов, активированного угля и флокулянта создает благоприятные условия для захвата разных форм микроэлементов в угольный концентрат и определения их валового содержания в подземных водах без сложной предварительной подготовки проб.

Описанным способом концентрируются марганец, свинец, никель, галлий, молибден, ванадий, олово, медь, хром, серебро и некоторые другие элементы, рассмотрение которых не входит в задачи данной работы.

Степень концентрирования микроэлементов зависит от $\mathrm{pH}$ анализируемой воды. Оптимальные результаты получаются при $\mathrm{pH}$ 5,0-5,5. Әто подтверждает и построение градуировочных графиков по двум типам эталонов, приготовленных концентрированием микроэлементов из эталонных растворов согласно описанной методике и непосредственным введением эталонных растворов элементов и реактивов в угольный порошок. При $\mathrm{pH} 7,0-7,5$ получаются уже несколько заниженные результаты: для марганца, никеля, олова, меди, хрома и серебра на $10 \%$, для молибдена и ванадия на $20 \%$. На галлий и цинк изменение рН от 5,0 до 7,5 не действует.

Подземные воды имеют $\mathrm{pH}$, как правило, около $7,0-7,5$, поэтому в полевых условиях можно или доводить $\mathrm{pH}$ воды до $5,0-5,5$, или осуществлять концентрирование при естественной кислотности воды, следя за тем, чтобы эталонные растворы для приготовления эталонов-концентратов имели близкую к водам кислотность.

Спектральный анализ концентратов микроэлементов проводится на спектрографе ДФС-8 с дифракционной решеткой 1200 штрих/мм. Высокая разрешающая способность прибора дает возможность анализировать концентраты с большим содержанием железа, что значительно упрощает схему концентрирования, так как большинство надежных групповых органических реактивов вступают в реакцию и с железом, а его отделение от микроэлементов связано с неизбежными потерями последних и другими трудностями.

Непрерывное введение порошков концентратов в дугу осуществляется способом просыпки: полуавтоматические установки просыпки (УСА-5) весьма доступны и широко применяются при полуколичественном анализе порошковых проб, в частности при металлометрической съемке в геологии. Однако способ просыпки в приложении к тонкоизмельченным угольным концентратам неэффективен из-за их плохой сыпучести. Этот недостаток устраняется путем смешивания концентрата с хорошосыпучим гранулированным углекислым литием, который обеспечивает и надежную стабилизацию температуры дуги независимо от состава концентрата. Равномерная и непрерывная просыпка порошка концентрата в дугу с постоянной температурой подавляет фракциониро- 
ванное испарение элементов и тем самым уменьшает влияние состава концентрата на результаты анализа.

Подготовка активи рованного угля. Продажный активированный уголь марки ОУ требует дополнительного измельчения и очистки от примесей металлов (марганца, меди). Измельчение проводится в вибромельнице. Вместо стальных стаканов нами применены полиэтиленовые банки диаметром 50 мм и высотой 60 мм. Они заполняются на одну треть стальными шариками диаметром 7 мм и $1-2$ г угля. На виброустановке мельницы помещается 15 банок. Продолжительность измельчения - 30 мин.

Измельченный уголь подвергается часовой очистке 1-нормальной азотной кислотой (1 часть угля, 5 частей кислоты) при температуре кипения. После фильтрования угля на воронке Бюхнера процедура кислотной обработки повторяется еще четыре раза, а затем уголь промывается горячим бидистиллятом воды до $\mathrm{pH} 5-6$. Очищенный уголь высушивается при $150^{\circ} \mathrm{C}$ и засыпается в плотно закрытые банки. Чистота угля проверяется спектральным анализом.

Поскольку свойства угля в разных партиях могут быть несколько различными, целесообразно подготовить его сразу в большом количестве (например 500 2), чтобы работать год и больше на одной партии. При длительном хранении тонкий порошок угля настолько уплотняется, что комочки его не распадаются в воде даже при сильном встряхивании, а суспензия получается не чисто черной, а сероватой. Поэтому желательно перед употреблением уголь повторно высушить и разрыхлить.

Для работы в полевых условиях уголь предварительно фасуется в маленькие пробирочки по 150 мг в каждую.

Р астворы реакти вов готовятся на ацетоне в следующих концентрациях: 8 -оксихинолин $-5 \%$, таннин $-2 \%$, тионалид $-1 \%$. Раст. воры должны быть всегда свежими. Поскольку реактивы содержат иногда примеси определяемых элементов, следует проверить их пригодность по слепому опыту. Количества прибавляемых к пробе воды растворов 8-оксихинолина и тионалида выбираются так, чтобы при стоянии в воде они давали не обильный осадок, а едва видную муть.

Раствор флокулянта - 0,1\%-ный водный раствор полиакриламида. Следует отметить, что препараты полиакриламида не все одинаково эффективны. Поэтому, готовя раствор из нового препарата, необходимо опытным путем корригировать количество прибавляемого раствора флокулянта.

Раствор смешанного индикатора (Лурье, 1971): 0,2\%-ный раствор метилового красного в спирте и $0,1 \%$-ный раствор метиленовой синей в спирте смешивают в соотношении 1:1. Индикатор при значениях $\mathrm{pH}$ выше 5,5 имеет зеленую, а ниже - интенсивную красно-фиолетовую окраску. Для регулирования $\mathrm{pH}$ проб воды раствор соляной кислоты разбавляется в соотношении $1: 5$.

Измерение объемов реактивов и их введение в пробы воды проводится $T$-образными полиэтиленовыми дозаторами, существенно облегчающими работу в полевых условиях.

Приготовление гранулированного углекислого л и т и я. Неудовлетворительная сыпучесть продажного углекислого лития квалификацией «х. ч.» или «ос. ч.» не позволяет использовать его для просыпки в аппарате УСА-5. Для улучшения сыпучести порошок реактива слегка смачивается $20 \%$-ным раствором глюкозы и продавливается с помощью шпателя из оргстекла через капроновое сито (диаметр отверстий 0,5 м.м). Влажные зерна реактива собираются тонким слоем на листе кальки и высушиваются при $150^{\circ}$. Высушенный продукт ссыпается в банку 
и неоднократно перекатывается для придания зернам более округлой формы. Размер зерен $0,3-0,5$ мм. Чистота гранулированного углекислого лития проверяется спектральным анализом.

Концентрирование микроэлементов. I этап. Для отбора пробы и концентрирования микроэлементов применяются чистые 1,5-2-литровые полиэтиленовые склянки с делением на $1 \Omega$. При длительном хранении желательно держать в них $1-2$ мл хлороформа для подавления жизнедеятельности микроорганизмов. Перед отбором пробы склянка тщательно ополаскивается исследуемой водой и заполняется до метки $(1 \Omega)$. Затем дозаторами вводится по 3 мл каждого реактива и 150 мг угля из пробирочки в следующем порядке: 8-оксихинолин, таннин, тионалид, уголь. После прибавления каждого реактива и угля проба сильно встряхивается и оставляется до момента доставки ее в лабораторию, причем осадок угля желательно отделять не ранее одних и не позднее четырех суток. Для каждой пробы воды готовятся параллельно два концентрата.

Если концентрирование микроэлементов проводится при $\mathrm{pH}$ 5,0-5,5, то к $1 \Omega$ пробы прибавляются из дозаторов 1 м $\Omega$ смешанного индикатора и по маленьким порциям соляная кислота до окрашивания воды в интенсивный красно-фиолетовый цвет. Далее поступают, как указано выше.

Қонцентри рование микроэлементов. II этап. После доставки проб воды в лабораторию проводится флокуляция суспензии концентрата. Содержимое склянки хорошо встряхивается, прибавляется $4-5$ мл 0,1\%-ного раствора полиакриламида и опять энергично встряхивается в течение 1 мин. Если через 2-3 мин не начинается выпадение крупных агрегатов осадка, прибавляется еще $4-5$ мл флокулянта, содержимое вновь встряхивается и оставляется на 20-30 мин. По истечении этого времени происходит образование крупных агрегатов осадка и просветление раствора. Прибавлять флокулянт в большом избытке нежелательно: от этого образуются прилипающие к стенкам склянки осадки и забиваются поры фильтра. Фильтрование осадка концентрата проводится на воронке Бюхнера диаметром 5 cм через бумагу «белая лента». Осадок вместе с фильтром выдерживается в течение часа в сушильном шкафу при температуре $100-105^{\circ}$. Высушенный концентрат ссыпается на листок кальки и раздавливается стеклянной лопаточкой в порошок. Хранится концентрат в пакетах из кальки.

Если приходится анализировать воды с содержанием железа выше 5 мг/л, поступают следующим образом. Концентрат после высушивания взвешивается, дополняется угольным порошком до 250 или 300 мг, и смесь тщательно перемешивается. Операции с эталонами аналогичны.

Когда появляется необходимость в бо́льшем количестве концентрата, например при повторных анализах в разных областях спектра или при озолении с целью повысить чувствительность анализа, для концентрирования берется $5 \Omega$ воды и к пробе прибавляется $10 \mu л$ растворов реактивов и 500 мг угля. Озоление концентрата и анализ золы в данной работе не проводились. Этот вариант анализа требует доработки.

Спектральный анализ концентр а та ведется на спектрографе ДФС-84 с дифракционной решеткой 1200 штрих/мм в первом порядке при следующих условиях: сила тока дуги (от генератора ДГ-2) $23 A$; время экспозиции - два раза по 30 сек, т. е. спектр концентрата снимается на одно место фотопластинки дважды; ширина щели спектрографа - 0,01 мм. Щель освещается через 3-линзовую конденсорную систему и 3-ступенчатый ослабитель. Диафрагма среднего конденсора открыта полностью, на нее фокусируется средняя часть факела дуги. Фотопластинки - спектральные, тип 2, 15 ед. по ГОСТу. 
Из общего количества концентрата (около 150 мг) отмеряется соответствующим ковшом 120 мг и смешивается в маленькой баночке из оргстекла с равным количеством гранулированного углекислого лития, отмеренного тем же ковшом. Полученная смесь засыпается в дугу на установке УСА-5 ковшом № 3 вместимостью 90 ме. Чтобы очистить концы электродов, вибратора и направляющей трубки от возможных остатков предыдущего концентрата, перед сжиганием следующего через дугу пропускается одна порция чистого гранулированного углекислого лития.

Фотопластинки проявляются в растворе следующего состава: сульфит натрия -100 г, гидрохинон -5 г, бура -4 г, борная кислота -16 г, бромистый калий -12 , фенидон $-0,2$ 2, вода - до $1 \Omega$. В этом фенидонгидрохиноновом проявителе (Микулин, 1972) изменено соотношение буры и борной кислоты в пользу последней. В результате этого процесс проявления протекает медленно, равномерно, с хорошей воспроизводимостью. Время проявления при температуре $20^{\circ}-10$ мин.

Значения почернений спектральных линий определяются на микрофотометре МФ-4 при ширине и высоте измерительной щели 0,3 и 10 мм соответственно. Применяется логарифмическая $S$-шкала. Эти значения переводятся в интенсивности с помощью характеристической кривой по Калькеру и Кассельманну (Calker, Kasselmann, 1963). Градуировочные графики строятся в координатах $\lg I-\lg C$ по концентратам-эталонам, приготовленным согласно методике концентрирования микроэлементов в пробах. Для проверки и уточнения положения градуировочных графиков на каждую фотопластинку снимается и контрольный эталон. Почернения спектральных линий измеряются на одной из трех ступенек спектра в зависимости от величины почернения, поэтому и графики строятся для трех ступенек. Это дает возможность по одной и той же линии находить содержание элемента в широких пределах. Содержание микроэлементов определяется по абсолютным интенсивностям без применения элемента сравнения, что существенно упрощает анализ большой группы элементов.

\section{Таблица}

Чувствительность и точность химико-спектрального анализа подземных вод

\begin{tabular}{c|c|c|c}
\hline $\begin{array}{c}\text { Микро- } \\
\text { элемент }\end{array}$ & $\begin{array}{c}\text { Аналитическая } \\
\text { линия, } \AA\end{array}$ & $\begin{array}{c}\text { Нижний пре- } \\
\text { дел опреде- } \\
\text { ления, мкг/л }\end{array}$ & $\begin{array}{c}\text { Коэффициент } \\
\text { вариации, \% }\end{array}$ \\
\hline $\mathrm{Mn}$ & 2801,06 & 0,4 & 14 \\
$\mathrm{Mn}$ & 2983,86 & 2,0 & 14 \\
$\mathrm{~Pb}$ & 2833,07 & 0,2 & 12 \\
$\mathrm{Ga}$ & 2843,64 & 0,2 & 10 \\
$\mathrm{Cr}$ & 3014,76 & 0,2 & 11 \\
$\mathrm{Ni}$ & 3060,81 & 0,2 & 7 \\
$\mathrm{Mo}$ & 3170,35 & 0,2 & 12 \\
$\mathrm{Sn}$ & 3175,02 & 0,2 & 12 \\
$\mathrm{~V}$ & 3183,41 & 0,2 & 9 \\
$\mathrm{Cu}$ & 3273,96 & 0,4 & 10 \\
$\mathrm{Ag}$ & 3280,68 & 0,03 & 9 \\
$\mathrm{Zn}$ & 3302,59 & 5,0 & 8
\end{tabular}

Чувствительность и точность химико-спектрального анализа подземных вод приведена в таблице.

Предложенная здесь методика применялась в Институте геологии АН ЭССР для определения микроэлементов в подземных водах Эстонии с целью установления их роли в процессах загрязнения и самоочищения. 


\section{ЛИ Т Е Р А Т Р А}

Анд ре е в П. Ф., Ч у м а ен ко А. П. 1961. Исследование процессов адсорбции некоторых комплексных соединений тяжелых металлов на активированном угле. Ж. прикл. химин, 34, № 10.

Благов И. С., Коткин А. М., Фоменко Т. Г. 1960. Осветление шламовых вод полиакриламидом на углеобогатительных фабриках. М.

Г у с яцкая Э. В., Л огин о в а Л. Г. 1956. Руководство по спектральному определению микроэлементов в сухих остатках маломинерализированных природных вод. М.

Е ременко В. Я. 1969. Спектрографическое определение микроэлементов (тяжелых металлов) в природных водах. Л.

К а п л н Б. Я., М е и с о в Ю. И., П е т о в а Е. И. 1974. Использование высокомолекулярных флокулянтов для группового концентрирования микропримесей при химико-спектральном анализе соединений редкоземельных элементов. В сб.: Оптические методы контроля химического состава материалов. М.

Ки бисовГ. И., Кржи жановская В. А., Кубасова Н. Б., Чучина В. Е. 1970. Об испарении тонкодиспергированных веществ в разрядах дуги и низковольтной искры при количественном спектральном анализе веществ пронзвольного состава. Ж. прикл. спектроскопии, 13, № 6.

Когано в ский А. М., Кл и м ен о Н. А. 1974. Физико-химические методы очистки промышленных сточных вод от поверхностно-активных веществ. Кнев.

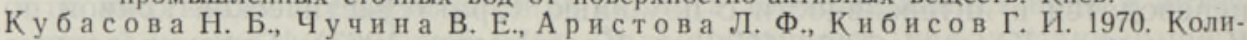
чественный спектральный анализ веществ произвольного состава. Ж. прикл. спектроскопин, 12, № 5 .

Куз нецов Ю. В., Щебетковски й В. Н., Т русов А. Г. 1974. Основы очистки воды от радиоактивных загрязнений. М.

Л урье Ю. Ю. 1971. Справочник по аналитической химни. М.

Лурье Ю. Ю., Рыбникова А. И. 1974. Химический анализ пронзводственных сточных вод. М.

Ми кулин В. П. 1972. Фотографический рецептурный справочник. М.

М и л л е р А. Д., С те п а н в П. А. 1959. Спектральное определение микроэлементов в водах и вытяжках на основе соосаждения с сульфидом кадмия. Обмен опытом, вып. 17. (Всесоюз. науч.-исслед. ин-т методики и техники разведки). Л.

М и тчел Р. Л. 1961. Определение следов элементов в растениях и других биологических объектах. В кн.: Анализ следов элементов. М.

Т арковская И. А., Горб енко Ф. П., Е мельянов В. Б., Олевински й М. И. 1965. Концентрирование микропримесей при помощи окисленного угля. Тр. комиссии по аналит. химии, 15.

Цг эн Сянь-Фу, К у з и Н И. А., Т а уш к ан ов В. П. 1963. Очистка урана от тяжелых металлов на активированном угле. Ж. прнкл. химии, 36, № 4.

$\mathrm{C}$ a 1 ke r J. van, Ka s selm a n n H. 1963. Untersuchungen über eine neue Methode zur Auswertung photographischer Messgrößen. Z. analyt. Chem., 198, Nr. 1.

Jackwerth E., Lohmar J., Wittler G. 1974. Zur Spurenanreicherung am Aktivkohle. Bestimmung von Elementspuren in Wolframpulver. Z. analyt. Chem., 270, Nr. 1.

Ннститут геологии

Академии наук Эстонской ССР

Поступила в редакцию

3/VI 1975

\section{E. JOHANNES}

\section{AKTIIVSÖE KASUTAMINE MIKROELEMENTIDE GRUPIVIISILISEKS KONTSENT- REERIMISEKS PÖHJAVEE KEEMILIS-SPEKTRAALSEL ANALUUSIL}

Esitatakse keemilis-spektraalse analüüsi metoodika, mis pōhineb põhjavee mikroelementide $\mathrm{Mn}, \mathrm{Pb}, \mathrm{Ga}, \mathrm{Cr}, \mathrm{Ni}, \mathrm{Mo}, \mathrm{Sn}, \mathrm{V}, \mathrm{Cu}, \mathrm{Ag}$ ja $\mathrm{Zn}$ kontsentreerimisel körge peenestusastmega aktiivsöe pulbrile 8-oksükinoliini, tanniini ja tionaliidi manulusel kahes etapis: 1) reaktiivide ja söe lisamine veeproovile vahetult veevõtukohas; 2) kontsentraadi eraldamine laboratooriumis filtreerimise teel, flokuleerides peendispersse söesuspensiooni eelnevalt polüakrüülamiidega.

Kontsentraatide analüüsiks on kasutatud difraktsioonvõrega spektrograafi DFS-8 ja 
poolautomaatset vibropuisteseadet USA-5. Peene söepulbri puistatavuse parandamiseks ja vahelduvvoolukaare temperatuuri stabiliseerimiseks lisatakse kontsentraatidele granuleeritud liitiumkarbonaati. Viimase valmistamise metoodikat on artiklis üksikasjalikult kirjeldatud. Analüüsi ruutkeskmine viga on elemendist olenevalt $7-14 \%$.

Kirjeldatud metoodikat on kasutatud Eesti pōhjavee mikroelementide määramiseks selgitamaks nende osalemist vee reostumis- ja isepuhastusprotsessides.

\section{E. JOHANNES}

\section{ANWENDUNG VON AKTIVKOHLE BEI DER CHEMISCH-SPEKTROGRAPHISCHEN ANALYSE DES GRUNDWASSERS, WO DIE MIKROELEMENTE GRUPPENWEISE KONZENTRIERT WERDEN}

Bei der hier beschriebenen Methodik der chemisch-spektrographischen Analyse werden die Grundwasser-Mikroelemente $\mathrm{Mn}, \mathrm{Pb}, \mathrm{Ga}, \mathrm{Cr}, \mathrm{Ni}, \mathrm{Mo}, \mathrm{Sn}, \mathrm{V}, \mathrm{Cu}, \mathrm{Ag}$ und $\mathrm{Zn}$ auf fein zerkleinertem Pulver der Aktivkohle in Gegenwart von 8-Oxychinolin, Tannin und Thionalid konzentriert, und zwar in 2 Stufen: 1) Reagenzien und Kohle werden der Wasserprobe unmittelbar am Wasserentnahmeort beigefügt: 2) das Konzentrat wird im Labor durch Filtrieren abgesondert, indem man vorher die fein verteilte Kohlensuspension durch Polyakrylamid ausflockt.

Zur Analyse der Konzentrate werden ein Gitterspektrograph DFS-8 und ein halbautomatisches Vibrator-Streugerät USA-5 gebraucht. Zur Steigerung der Streufähigkeit des feinen Kohlepulvers und zum Stabilisieren der Temperatur des Wechselstromlichtbogens wird den Konzentraten granuliertes Lithiumkarbonat hinzugefügt, dessen Herstellungsweise im Aufsatz ausführlich beschrieben wird. Die relative Standardabweichung der Analyse beträgt je nach dem Element $7-14 \%$.

Die betreffende Methodik der chemisch-spektrographischen Analyse ist bei der Bestimmung der Mikroelemente im Grundwasser Estlands angewandt worden, namentlich bei der Herausklärung der Rolle dieser Elemente im Verunreinigungs- und Selbstreinigungsproze $B$ der Gewässer. 